\section{Quando o 'êxito técnico' se recobre de 'sucesso prático': o sujeito e os valores no agir profissional em saúde}

When a 'technical triumph' is deemed a 'practical success': the subject and the values of professional work in healthcare

\section{Lilia Blima Schraiber ${ }^{1}$}

Os termos 'êxito técnico' e 'sucesso prático' referem conceitos que qualificam as práticas de saúde cotidianas ${ }^{1}$. Permitem compreender, na assistência prestada, as opções profissionais e as concepções de 'boa prática' que estão em jogo. Tomo-os, em torno da articulação sujeito-valores, como mote às considerações de Campos, e porque, quando o acerto técnico se recobre de sucesso prático, concorrem no agir profissional três importantes atributos: o de ser 'interativo', 'crítico' e 'reflexivo'. Todos dizem respeito às mediações entre os conhecimentos científicos e a prática profissional e também às escolhas dos profissionais para sua ação.

Ao debruçar-se sobre a noção de 'cuidado' e buscando esclarecer os aspectos convergentes e os divergentes entre práticas de cuidado e práticas de tratamento, Ayres ${ }^{1}$ aponta para a possibilidade de se alcançar êxito técnico sem que se alcance o cuidado, mais identificado a sucessos práticos. Mostra, assim, que uma resposta assistencial baseada em êxitos técnicos, em que a proposta terapêutica se resume à adequada administração, do ponto de vista científico, dos recursos tecnológicos (diagnósticos e terapêuticos, e mesmo preventivos), é uma resolução de problemas de saúde (mais precisamente de patologias) de ordem diversa daquela do sucesso prático. É também uma visão terapêutica que se reduz a protocolos cada vez mais padronizados da ação, uma técnica resumida a instruções do como proceder, retirando-lhe a potencia reflexiva.

O êxito técnico está fundado no olhar e nos saberes da biomedicina da Modernidade. Expressa a própria medicalização da vida social, ao fornecer uma compreensão de que os sujeitos sociais podem e devem ser tomados apenas em suas dimensões de corpo-organismo, o que se torna interpretação hegemônica dos adoecimentos. Na segunda metade do século XX, ocorre a progressiva transformação tecnológica das ciências e das técnicas, acentuando seu lado procedimental e mecânico, e estabelecendo o uso dos recursos tecnológicos como referência de boa prática ${ }^{2}$, em detrimento da reflexão e da criatividade, nas abstrações das ciências (teoria e conceitos) e nas engenhosidades das técnicas (invenções de arte) ${ }^{3}$.

Sintetizando: O êxito técnico refere-se, sem dúvida, a um sucesso, mas um sucesso em relação a um "como" fazer. Não faz parte de suas aptidões definir os "quê fazer" (p. 31). E chamo atenção que na cultura da medicalização a distinção entre este 'como' e o 'quê' se esmaece, já parecendo o mesmo. 'O que devemos fazer' passa a ser compreendido por 'como faremos', de que decorre uma representação de boa prática profissional como aquela que escolhe e administra as tecnologias de modo adequado, cientificamente.

Esta concepção de sucesso representa parte do potencial do profissional como sujeito, reduzindoo ao empreendimento de encontrar as tecnologias adequadas, com base no diagnóstico da patologia. Por isso, significa uma adequação em abstrato: a todos os casos da doença, que já não são mais nem os doentes, nem aquele doente. $\mathrm{O}$ mesmo poderse-ia postular por referência a questões de prevenção. Nessas situações, a mediação tecnológica conhecimento-prática leva o profissional a encerrar seus julgamento e decisão assistenciais, ao identificar os procedimentos derivados da doença, não mais se indagando se, naquele caso e contexto, eles são realmente adequados do ponto de vista prático: serão adequados a outros casos análogos que já vivenciou ou compartilhou com outros profissionais (respeitando o seu 'saber prático' ou a arte da profissão)? Serão adequados à vida cotidiana dos sujeitos sobre os quais irá intervir?

São a essas perguntas que responde o sucesso prático, ao ser o alcance do outro, no projeto de assistir e na assistência prestada; o outro da relação, que se pode alcançar se e quando há interação, e a relação é intersubjetividade ${ }^{1}$. Não é a realização do exclusivo ponto de vista do profissional, que, de algum modo, "convenceu" ao outro de sua razão científica e tecnológica, lembrando que este convencer raramente é se colocar em acordo dialógico com o outro, como seria o exercício ético da autoridade, ou de poder nas relações de autoridades desiguais. Nos dizeres de Arendt": O poder corresponde à habilidade humana não apenas para agir, mas para agir em concerto (p. 36).

O exercício da subjetividade, em que o profissional se dispõe dialogicamente, não se dá como reiteração do que já é, como mesmice, mas como trocas e mudanças ${ }^{1}$. A relação é, neste caso, intersubjetiva, em que o profissional, que já é técnico, já se vale da ciência e das tecnologias como a tradição da técnica, reage criticamente a essa tradição, pois se modifica como sujeito e modifica sua ação pelo 
que recebe do outro com quem interage. Este compartilhar atualiza a técnica, não o tecnológico. Repõe a técnica, inovando-a, ao dar-lhe nova engenhosidade, permitindo pensar o que fazer e o que não fazer com o tecnológico, por revestir-se de novos componentes para o julgamento acerca da intervenção (o que fazer).

O agir compartilhado é a interação e permite a construção comum de valores quanto à assistência $\mathrm{e}$ seus resultados. Funda a ação, primeiro, em um 'quê fazer' ao qual se subordina o 'como fazer', momento em que, então, serão buscadas as melhores formas de uso das tecnologias disponíveis, ou mesmo se há algo a se fazer, ou não, desse ponto de vista tecnológico. E nesse sentido, será um agir critico, o que não significa excluir as tecnologias, mas indagar de sua conveniência: será esta a tecnologia que devo usar neste caso? Será que devo usá-la neste momento do caso? Tais perguntas não anulam as propriedades cientificas ou tecnológicas dos recursos diagnósticos ou terapêuticos, mas colocam dúvidas quanto a suas pertinências ilimitadas, apontam para limites de sua eficácia e oportunidade.

Com isto também se está considerando que no contexto prático, da vida cotidiana e de quando se apresenta à prática do profissional, o doente ou usuário do serviço é o sujeito da maior autoridade para dizer o que seria, em seu caso, um bom resultado da intervenção, o que realizaria seus sonhos e esperanças, sendo, enfim, um sucesso.

Como aponta Campos 5 , há que se compor, e acrescento com primazia, outras modalidades de articular o científico à prática profissional para além da mediação tecnológica. Concordo com sua afirmação de que a arte da técnica é uma dessas modalidades, tal como considerei acerca da prática dos médicos em particular, examinando seu duplo caráter técnico, no saber que provém da ciência e no que provém da experiência, saber prático ${ }^{2}$. Neste caso, a abertura a "um outro" dá-se na relação que o profissional realiza com si mesmo. Expressa uma prática reflexiva; o pensar sobre sua atuação, ao considerar seu saber prático, suas experiências anteriores, e refletir sobre a intervenção que fará, sem que esta se resuma apenas a usar os recursos cientificamente adequados. Esta é uma reflexão que, tal qual a prática interativa com o outro, leva o profissional a renovar-se como sujeito, evitando que, como agente de prática, reproduza sempre as mesmas referências assistenciais. Alguns médicos mencionam esse pensar como a recuperação de um julgamento clínico crítico, que avaliam como extremamente necessário à boa prática² .

Efetivamente, a própria ciência se auto define em termos das certezas que consegue alcançar nos diversos ramos de seus conhecimentos e em quais casos.
Mas já não pode assegurar se este ou aquele sujeito concretamente está situado dentro ou fora desses seus limites, para uma intervenção mais segura. E, sobretudo, ao consolidar-se como teoria das doenças, está muito distante de alcançar os desejos e as expectativas dos sujeitos concretos e particulares quanto aos resultados das intervenções. Em alguns casos ou situações pode haver convergência; noutros não. O problema é que, de antemão, os profissionais não podem saber em quais a convergência ocorrerá, daí ser relevante uma prática reflexiva.

Mas expor a racionalidade tecnológica a alterações é difícil. De outro lado, é necessário para outra visão de boa prática, a de 'cuidado'. De uma dupla referência: como cuidado ao outro e cuidado a si mesmo (o profissional). Estes dois sentidos de cuidado estão no agir que é interativo, crítico e reflexivo. Enfatizo que esses três atributos são conquistados pelo profissional, como opções de sujeito, não sendo qualidades naturais da prática em saúde.

Demandando tais conquistas, estão alguns dos problemas contemporâneos que cercam as relações dos profissionais com seus modos de agir, tais como, a desumanização dos serviços de assistência e das intervenções profissionais, a crise de confiança nas relações com a supremacia dos meios tecnológicos, a alienação profissional no agir progressivamente parcelar e empresariado ${ }^{2}$. Em todos esses casos, há uma renúncia, por vezes relutante, em 'ser sujeito' nos vários sentidos antes apontados. Renúncia na qual os profissionais abdicam desta ou daquela parcela de poder decisório, pela adoção de exercício de subjetividade voltado para a reiteração de si mesmo como agente tecnológico e das suas necessidades individuais.

De outro lado, é importante lembrar, como o faz Campos ${ }^{5}$, da existência de mais de uma possibilidade mediadora entre o saber e o fazer nas práticas profissionais, o que será sempre tensão nas escolhas do profissional e desafios para renovar-se como sujeito.

\section{Referências}

1. Ayres JRCM. Cuidado: trabalho e interação nas práticas de saúde. Rio de Janeiro: CEPESC, IMS/UERJ, Abrasco; 2009. Schraiber LB. O médico e suas interações: a crise dos

2. vínculos de confiança. São Paulo: Hucitec; 2008. Schraiber LB, Mota A, Novaes HMD. Tecnologias em

3. Saúde. In: Escola Politécnica de Saúde Joaquim Venâncio, organizadora. Dicionário da educação profissional em saúde. Rio de Janeiro: Editora Fiocruz; 2006. p. 248-257.

4. Arendt H. Sobre a violência. Rio de Janeiro: Relume Dumará; 1994.

5. Campos GWS. A mediação entre conhecimento e práticas sociais: a racionalidade da tecnologia leve, da práxis e da arte. Cien Saude Colet 2011; 16(7)3033-3040. 